\title{
INTERPLAY BETWEEN VITAMIN D STATUS AND ANTIVIRAL THERAPY AMONG CHRONIC HEPATITIS C EGYPTIAN PATIENTS
}

\author{
By \\ MOUSTAFA HAMED ABD ELALIM ${ }^{1}$, DOAA ZAKARIA ZAKY ${ }^{1}$, IBRAHIM \\ ABD EL GHANY MOTAWAE ${ }^{2}$, NESREEN A MOHAMED ${ }^{3}$, \\ AND ADLY NABIH NAGIB \\ Departments of Tropical Medicine ${ }^{1}$, Internal Medicine ${ }^{2}$ and Clinical Pathology, \\ Faculties of Medicine, Ain Shams University ${ }^{1}$, Cairo 11566 and \\ El-Menia University², El-Menia, Egypt

\section{Abstract}

Vitamin D has been shown to play an important immunomodulatory role; deficiency of vitamin $\mathrm{D}$ has been recently associated to the lack of response to antiviral therapy in chronic hepatitis $\mathrm{C}$ patients. This study evaluated the interrelationship between serum level of vitamin $\mathrm{D}$ and early response to antiviral therapy in Egyptian patients with chronic $\mathrm{HCV}$ infection. A total of 45 patients with chronic HCV infection who received antiviral treatment (Pegylated interferon and Ribavirin), their vitamin D serum level was assessed once at the start of treatment and 12 weeks later, when the EVR was determine by Quantitative HCV-RNA by PCR.

The results showed that vitamin D status has no correlation with viral load and hepatitis activity by biopsy and without significant association between vitamin D deficiency and the antiviral therapy response. However, there was significance improvement in level of vitamin D after 12 weeks of receiving the antiviral therapy of HCV.

Key words: Egypt, Chronic Hepatitis C Patients, Vitamin D, Antiviral Therapy

\section{Introduction}

The prevalence of vitamin D insufficiency ranged from a minimum of about $50 \%$ to a maximum of perhaps $75 \%$ or greater (Gorden et al, 2008). The Committee of the Institute of Medicine concluded that persons at risk of vitamin D deficiency at serum 25 $(\mathrm{OH})$ concentration $<30 \mathrm{nmol} / \mathrm{L}(12 \mathrm{ng} / \mathrm{ml})$. some people are potentially at risk for inadequacy at levels ranging from $30-50 \mathrm{nmol} / \mathrm{L}$ $(12-20 \mathrm{ng} / \mathrm{ml})$. Practically all people are sufficient at levels $>=50 \mathrm{nmol} / \mathrm{L}(>=20 \mathrm{ng} / \mathrm{ml})$, the committee stated that $50 \mathrm{nmol} / \mathrm{L}$ is the serum $25(\mathrm{OH}) \mathrm{D}$ level that covers the needs of $97.5 \%$ of the population. Serum concentration $>125 \mathrm{nmol} / \mathrm{L}(>50 \mathrm{ng} / \mathrm{ml})$ are associated with potential adverse effect.

There is relationship between vitamin D and other liver diseases, in the view of bile acid dependent uptake of vitamin D and its hepatic metabolism its responsible to expect an association between vitamin $\mathrm{D}$ status and both cholesteric and non cholestatic chronic liver disease and serum concentration of 1 , $25(\mathrm{OH})_{2}$ vitamin $\mathrm{D}$, they decrease in pa- tients with cirrhosis versus non-cirrhotic patients (Fisher et al, 2007; Southern et al, 2010).

A significant correlation between $25(\mathrm{OH})$ vitamin D level and stage of fibrosis because vitamin $\mathrm{D}$ has antifibrinogenic effect and anti-inflammatory effect so with lower 25 $(\mathrm{OH})$ vitamin $\mathrm{D}$ the stage of fibrosis is increased and severity of necroinflammatory activity was observed, so low vitamin D is linked to severe fibrosis and low sustained virological response on interferon therapy and increase the risk of side effect of interferon (Abu Mouch et al, 2011).

Vitamin D supplementation was reported to improve the probability of achieving sustained virological response when combined with antiviral treatment against hepatitis $\mathrm{C}$ virus (HCV) and decrease $\mathrm{HCV}$ infectious virus production and vitamin $\mathrm{D}$ is an immune modulator that has direct effect on $\mathrm{T}$. cells and antigenst presenting immune cells and can directly and indirectly influence the differentiation and activity of CD4 T. cells (Mahon et al, 2003; Schauber et al, 2007). 
The anti-inflammatory and anti-fibrotic roles of vitamin $\mathrm{D}$ indicate that vitamin $\mathrm{D}$ has the potential to reduce $\mathrm{HCV}$-mediated liver disease and it is well established that vitamin D plays an important antibacterial role by regulating cathelicidin expression in human monocytes (Liu et al, 2006). Vitamin $\mathrm{D}$ also have analogous effects, as evidenced by the fact that vitamin $\mathrm{D}$ and its metabolites can synergize with IFN treatment to directly inhibit HCV RNA replication in vitro, several association studies have examined 25 $(\mathrm{OH}) \mathrm{D}$ levels in patients with chronic HCV and most of them not all, reported a positive correlation between $25(\mathrm{OH}) \mathrm{D}$ levels and the likelihood of achieving an SVR (Gal-Tanamy et al, 2011; Matsumura et al, 2012).

Studies by Abu-Mouch et al. (2011); Nemer et al. (2012); Mohamed et al. (2013); and others reported vitamin $\mathrm{D}$ as predictor for SVR with effective treatment of HCV by its antiviral activity.

The present study evaluated the interrelationship between vitamin D status and the response rate among Egyptian $\mathrm{HCV}$ infected patients to antiviral therapy and the effect of interferon therapy on vitamin D.

\section{Patients, Materials and Methods}

This study was conducted on group of chronic HCV patients who were eligible for combined ribavirin interferon therapy according to the protocol of Health Insurance Organization in Egypt in the period between January to June 2014. The study included 45 age and sex matched patients of those patients attending at Hepatolgy Center in the One Day Surgery Hospital in Samalout, El Minia Governorate to receive the treatment of Pegylated INF plus ribavirin 800-1200 $\mathrm{mg} /$ day $(10.6 \mathrm{mg} / \mathrm{kg} /$ day) for 48 weeks regimens. The patients enrolled were informed about the study purpose and gave written consent. All patients had both $(\mathrm{OH})$ vitamin D serum level and HCV RNA by quantitative PCR measured twice, the $1^{\text {st }}$ one immediately before treatment and the $2^{\text {nd }}$ after 12 weeks at the time of the early response assessment. Patients with one or more of the following criteria were excluded from the study: less than 18 or older than 60 (BMI $\geq 35$ ), or with renal impairment, abnormal calcium and phosphate level, or with special dietary habits as vegetarians or taking supplements including vitamin $\mathrm{D}$, or with low sun exposure due to any cause such as totally veiled or bedridden, also, patients with liver disease other than HCV.

All patients were subjected to detailed history, full clinical and physical examinations, complete liver profile, virological diagnosis by $\mathrm{HCV}$-antibodies, HBSAg, viral load by the quantitative PCR for HCV-RNA, vitamin D level measurement, abdominal ultrasound and liver biopsy (Ishak et al, 1995) to determine necroinflamation grade and liver fibrosis stage.

All patients had both $(\mathrm{OH})$ vitamin D serum level and HCV RNA by quantitative PCR measured twice, the 1st one immediately before treatment and the 2nd after 12 weeks at the time of the early response assessment. Serum HCV RNA level was quantified using QIAamp Viral RNA Mini Kit (Qiagen, Duesseldorf, Germany) for viral RNA extraction which was added to Brilliant QRT-PCR 1-step Master Mix, based on Taq-Man techno- logy, (Stratagene, La Jolla, USA) and real-time RT-PCR by Stratagene Mx3000P device. Serum 25 (OH)D concentration was analyzed by ELISA-kit (Immundiagnostik A G, Bensheim, Germany). Assay detected $25(\mathrm{OH}) \mathrm{D}$ concentrations as low as $6.4 \mathrm{nmol} / \mathrm{L}$.

Statistical analysis: Data was analyzed by PASW statistics 18. Numerical data were expressed as mean and standard deviation. Qualitative data were expressed as frequency and percentage. Chi-square test (Fishers exact test) was used for relation between qualitative variables. For quantitative data normally distributed, comparison between two groups was done using t-test. For quantitative and qualitative data not normally distributed, comparison was done by KruskalWallis test and Mann Whitney U test. Paired 
$\mathrm{t}$ test was used for quantitative paired data. A p-value $<0.05$ was considered significant.

\section{Results}

In the present study, only 4 patients were non-early responder, 45 patients were 29 male and 16 female with mean age $41.62 \pm 10.823$,

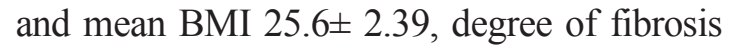

F1 was 19, F2 was 20 and F3 was 6, degree of activity A1 was 8, a2 was 32 and F3 was 5, and 25 patients used peganteron and 20 ones used pegaferon.

The details are shown in tables $(1,2,3,4$ and 5).

Table 1: Clinico-pathological criteria of studied population

\begin{tabular}{|l|l|l|}
\hline \multirow{2}{*}{ Variable } & \multicolumn{2}{|l|}{ Studied population } \\
\cline { 2 - 3 } Age & Number & Percent \\
\hline$\leq 40$ & 19 & 42.2 \\
\hline$>40$ & 26 & 57.8 \\
\hline Total & 45 & 100 \\
\hline SEX & \multicolumn{2}{|l|}{} \\
\hline Male & 29 & 64.4 \\
\hline Female & 16 & 35.6 \\
\hline Total & 45 & 100 \\
\hline BMI & \multicolumn{2}{|l|}{} \\
\hline M \pm SD & $25.6 \pm 2.39$ \\
\hline Range & $21-30$ \\
\hline Degree of fibrosis & \multicolumn{2}{|l|}{} \\
\hline F1 & 19 & 42.2 \\
\hline F2 & 20 & 44.4 \\
\hline F3 & 6 & 13.3 \\
\hline Total & 45 & 100 \\
\hline Degree of activity & \multicolumn{2}{|l|}{} \\
\hline A1 & 8 & 17.8 \\
\hline A2 & 32 & 71.1 \\
\hline A3 & 5 & 11.1 \\
\hline Total & 45 & 100 \\
\hline Response & \multicolumn{2}{|l|}{} \\
\hline EVR & 41 & 91.1 \\
\hline Non- responders & 4 & 8.9 \\
\hline Total & 45 & 100 \\
\hline
\end{tabular}

Table 2: Correlation between Vitamin D before treatment and PCR before treatment

\begin{tabular}{|l|c|c|c|c|c|c|}
\hline \multirow{2}{*}{ PCR } & \multicolumn{2}{|c|}{ Deficient } & \multicolumn{2}{c|}{ Sufficient } & \multicolumn{2}{c|}{ Chi-square test } \\
\cline { 2 - 5 } & NO. & $\%$ & No. & $\%$ & $\mathrm{x}^{2}$ & P-value \\
\hline high & 4 & $20.0 \%$ & 5 & $20.0 \%$ & & \multirow{2}{*}{0.024} \\
\hline Low viremia & 10 & $50.0 \%$ & 13 & $52.0 \%$ & 0.988 \\
\hline moderate & 6 & $30.00 \%$ & 7 & $28.0 \%$ & & \\
\hline
\end{tabular}

Low viremia $\left(16-2 \times 10^{5}\right) \mathrm{IU} / \mathrm{ml}$, moderate $\left(2 \times 10^{5}-1 \times 10^{6}\right) \mathrm{iu} / \mathrm{ml}$, high ( more than $\left.1 \times 10^{6}\right) \mathrm{iu} / \mathrm{ml}$ Sufficient vitamin D more than 30ng/dl; deficient vitamin D less than 30ng/dl. No significance between vitamin D and viral load by PCR before antiviral therapy treatment. 
Table 3: Relation of vitamin D before treatment with activity and fibrosis

\begin{tabular}{|c|c|c|c|c|c|c|c|}
\hline & \multicolumn{2}{|c|}{ Deficient } & \multicolumn{2}{|c|}{ Sufficient } & \multicolumn{2}{|c|}{ Chi-square test } \\
\hline & & No. & $\%$ & No. & $\%$ & $\mathrm{X}^{2}$ & P-value \\
\hline \multirow{3}{*}{ Activity } & A1 & 4 & $20.0 \%$ & 4 & $16.0 \%$ & \multirow{3}{*}{1.387} & \multirow{3}{*}{0.500} \\
\hline & $\mathrm{A} 2$ & 15 & $75.0 \%$ & 17 & $68.0 \%$ & & \\
\hline & A3 & 1 & $5.0 \%$ & 4 & $16.0 \%$ & & \\
\hline \multirow{3}{*}{ Fibrosis } & F1 & 7 & $35.0 \%$ & 12 & $48.0 \%$ & \multirow{3}{*}{0.77} & \multirow{3}{*}{0.681} \\
\hline & $\mathrm{F} 2$ & 10 & $50.0 \%$ & 10 & $40.0 \%$ & & \\
\hline & F3 & 3 & $15.0 \%$ & 3 & $12.0 \%$ & & \\
\hline
\end{tabular}

By comparing deficient vitamin $\mathrm{D}$ group and sufficient vitamin $\mathrm{D}$ group as regarding activity and fibrosis in liver biopsy before starting antiviral therapy showed no statistical significance.

Table 4: Responders and non-responders to Interferon therapy, as to Vit. D deficiency (normal level $>30 \mathrm{ng} / \mathrm{ml}$ )

\begin{tabular}{|l|c|c|c|c|}
\hline Variable & Responders & Non Responders & Total & P value \\
\cline { 1 - 4 } Deficient level $(<30 \mathrm{ng} / \mathrm{dl})$ & $17(85 \%)$ & $3(15 \%)$ & $20(44.4 \%)$ & \multirow{2}{*}{0.3} \\
\cline { 1 - 4 } Sufficient level $(\geq 30 \mathrm{ng} / \mathrm{dl})$ & $24(96 \%)$ & $1(4 \%)$ & $25(55.6 \%)$ & \multirow{2}{*}{ Not Significant } \\
\hline Total & $41(91.1 \%)$ & $4(8.9 \%)$ & $45(100 \%)$ & \\
\hline
\end{tabular}

Effect of vitamin D level status on early response of antiviral therapy without significance.

Table 5: Comparison of serum vitamin D level before and after treatment in all patients:

\begin{tabular}{|l|c|c|c|c|c|c|}
\hline \multirow{2}{*}{ Variable } & \multicolumn{2}{|c|}{ Before } & \multicolumn{2}{c|}{ After } & \multicolumn{2}{c|}{ Paired t-test } \\
\cline { 2 - 7 } & Mean & SD & Mean & SD & t & p-value \\
\hline Vit. D $(15-80 \mathrm{ng} / \mathrm{ml})$ & 32.00 & 13.09 & 46.76 & 18.03 & 5.019 & 0.000 \\
\hline
\end{tabular}

High significant improvement in vitamin D level, after 12 weeks of interferon therapy in all patients regardless of EVR.

\section{Discussion}

In the present study, the vitamin D was deficient in 20 patients (44\%) of patients, which agreed with Petta et al. (2010) who recognized that vitamin D deficiency was common among patients with chronic liver disease, and Artech et al. (2010) who evaluated 118 patients with chronic liver disease, $85 \%$ had $\mathrm{HCV}$ infection, more than $90 \%$ of them had $25(\mathrm{OH}) \mathrm{D}$ levels less than $32 \mathrm{ng} / \mathrm{ml}$, which was considered by many vitamin $\mathrm{D}$ experts to be the lower limit of the optimal range.

In the present study, there was no statistical significant difference between vitamin D status and degree of fibrosis and hepatitis activity by liver biopsy, which agreed with Esmat et al. (2014)

There was no significant effect of vitamin $\mathrm{D}$ level on the response of antiviral therapy of Egyptian chronic hepatitis $\mathrm{C}$ patients. The data agreed with Lange et al. (2012) who found no significant association between 25(OH)D3 serum level and SVR to INF based therapy in a cohort study of $317 \mathrm{HCV}$ genotype 1,4 patients, moreover Esmat et al. (2014) found that vitamin D supplementation in a dose of 15,000 IU/week (Cholecalciferol) during treatment course gave no significant impact on SVR in HCV genotype 4 patients out of 100 chronic HCV patients. Kiston et al. (2013) found no significant effect of baseline 25(OH) D3 status and sustained virological response on $274 \mathrm{CHC}$ patients.

On the contrary, Mohamed et al. (2013) reported that vitamin $\mathrm{D}$ deficiency predicted an unfavorable response to interferon- based treatment of HCV among fifty patients infected with HCV genotype 4 , he reported that responders to ribavirin plus pegylated interferon alpha 2a therapy had significantly higher baseline vitamin $\mathrm{D}$ levels than nonresponders. However, Petta et al. (2010) found an association between lower vitamin D serum levels and failure to achieve SVR in a retrospectively analyzed a cohort study of 167 patients treated with antiviral therapy for HCV. Also, Petta et al. (2010), Gal Tanamy et al. (2011) Abu-Mouch et al. (2011) and Kondo et al. (2013) studied genotypes 
other than 4 and evaluated the SVR not EVR as in the present study.

In the present study, there was highly significant improvement in the level of vitamin $\mathrm{D}$ post treatment among all patients, and this might be due to antiviral therapy that improved liver function including vitamin D hydroxylation, and thus antifibrotic activity of interferon (Ogawa et al, 2008). This also agreed with Grammatikos et al. (2014) who found that vitamin D level increase during antiviral therapy in $39 \%$ of $\mathrm{CHC}$ patients. They concluded that there was an association between the antiviral therapy response and 7 dehydrocholesterol reductase (DHCR-7) that converts 7-dehydrocholesterol to cholesterol, and thus removing the substrate from synthetic pathway of vitamin D and finally regulating vitamin D levels. Kitson and Roberts (2012) mentioned that the vitamin $\mathrm{D}$ is synthesized predominantly in the liver and functions as an important secosteroid hormone with pleiotropic effects, and its key regulatory role in calcium and bone homeostasis is well established, with increasing recognition that vitamin D regulates cell proliferation, differentiation, and has immunomodulatory, antiinflammatory and anti-fibrotic action. The non-skeletal effects are relevant in the pathogenesis and treatment of many causes of chronic liver disease. Vitamin D deficiency is frequently present in chronic liver disease and may predict non-response to antiviral therapy in CHC. They added that in liver transplant recipients severe vitamin $\mathrm{D}$ deficiency predicts, and vitamin D-supplementation prevents, acute cellular rejection. The role of vitamin $\mathrm{D}$ in activation and regulation of innate and adaptive immune systems may explain its importance in the above liver diseases.

García-Álvarez et al. (2014) stated growing evidence that vitamin $\mathrm{D}$ is related to $\mathrm{CHC}$ pathogenicity. They concluded that low vitamin $\mathrm{D}$ status in $\mathrm{CHC}$ patients was associated with a higher likelihood of advanced liver fibrosis and lower odds of sus- tained virologic response post pegIFN $\alpha /$ ribavirin therapy.

\section{Conclusion}

The outcome data showed that vitamin D status has no effect on early response of antiviral therapy in patients of HCV genotype 4 , but the highly significantly improvement of vitamin D level after the antiviral therapy.

Further study is ongoing to investigate the mechanism of improvement and will be published in due time, elsewhere

\section{References}

Abu Mouch, Z, Fireman, J, Jarchovsky, et al, 2010: Vitamin D supplement improve naïve patients treated with peg interferon and ribavirin. $45^{\text {th }}$ Annual Meeting of the liver (EASL) April 14-18, Vienna, Austria.

Arteh, J, Narra, S, Nair, S, 2010: Prevalence of vitamin D deficiency in chronic liver disease. Dig. Dis. Sci. 55, 9:2624-8.

Esmat, G, El Raziky, M, Elsharkawy, A, et al, 2014: Impact of vitamin D supplementation on sustained virological response in chronic hepatitis $\mathrm{C}$ genotype 4 patients treated by pegylated-

interferon/ribavirin. J. Interferon Cytok. Res. 35, 1:49-54.

Fisher, L, Fisher, A 2007: Vitamin D and parathyroid hormone in outpatients with non cholestatic chronic liver disease. Clin Gastroenterol Hepatol. 5:013 - 520.

Gal-Tanamy, M, Bachmetov, L, Ravid, A, Koren, R, Erman, A, TurKasp, R, et al, 2011: Vitamin D: an innate antiviral agent suppressing hepatitis $\mathrm{C}$ virus in human hepatocytes. Hepatology 54:1570-9.

García-Álvarez, M, Tenor, D, Jiménez, MA, Rodríguez, A, Fulgencio, M, 2014: Relationship of vitamin D status with advanced liver fibrosis and response to hepatitis $\mathrm{C}$ virus therapy: a meta-analysis. Hepatology 60, 5:1541-50.

Gorden, CM, Feldman, L, Sinclair, L et al, 2008: Prevalence of vitamin D. defeciency in healthy infant and toddlers. Arch. Pediatr. Adolesc. Med.162, 6:505-12.

Grammatikos G, Lange C, Susser S, Schwendy S, Dikopoulos N, et al, 2014: Vitamin D levels vary during antiviral treatment but are unable to predict treatment outcome in HCV genotype 1 infected patients. PLOS One 9, 2: e87974. 
Kiston, MT, Dore, GJ, George, J, et al, 2013: Vitamin D status does not predict sustained virologic response or fibrosis stage in chronic hepatitis C genotype 1 infection. J. Hepatol. 58: 46772.

Kitson, MT, Roberts, SK, 2012: D-livering the message: The importance of vitamin D status in chronic liver disease. J. Hepatol. 57, 4:897-909

Kondo, Y, Kato, T, Kimura. O, et al, 2013: Vitamin D3 supplementation improves the sensitivity of the immune response during PegINF/RBV therapy in chronic hepatitis patients. PLOS One 8, 5:e63672.

Lange, CM, Bibert, S, Kutalik. Z, et al, 2012: A genetic validation study reveals a role of Vitamin D metabolism in the response to Interferon-Alfa based therapy of chronic C. PLOS One 7, 7:e40159.

Liu, PT, Stenger, S, Li, H, Wenzel, L, Tan, BH, Krutzik, SR, et al, 2006: Toll-like receptor triggering of a vitamin D-mediated human antimicrobial response. Science 311:1770-3.

Mahon, BD, Wittke, A, Weaver, V, et al, 2003: The target of vitamin $D$ depend on the differentiation and activation of CD4 positive T.cells. J. Cell Biochem. 89:922-32.

Matsumura, T, Kato, T, Sugiyama, N, TasakaFujita, M, Murayama, A, Masaki T, et al, 2012: 25-hydroxyvitamin D3 suppresses hepatitis C virus production. Hepatology 56:1641-50.

Mohamed, AA, Sabry, NA, Abbassi, MM, et al, 2013: Vitamin D levels in Egyptian HCV patients (genotype 4) treated with pegylated interferon, Acta Gastroenterol. Belg. 76, 1:38-44.

Nemer, A, Mouch, A, 2012: Vitamin D improve viral response in hepatitis $\mathrm{C}$ genotype $2 \& 3$ naïve patients. World J. Gastroenterol.18:800-5.

Ogawa, T, Kamada, N, Ikeda, K, et al, 2009: Effect of natural INF on proliferation and appoptosis of hepatic stellate cells. Hepatol. Int. 3, 3:497-503.

Petta, S, Cammà, C, Scazzone, C, Tripodo, C, Di Marco, V, et al, 2010: Low vitamin D serum level is related to severe fibrosis and low responsiveness to interferon-based therapy in genotype 1 chronic hepatitis C. Hepatology 51: 1158-67

Schauber, J, Dorschner, R, Yamasakik, A, et al, 2007: injury enhances TRL2 function and antimicrobial peptide expression through avitamin D. dependent mechanism. J. Clin. Invest. 117:803-11.

Southern, P, El-Sayed, P, Fenton, L, et al, 2010: influence of vitamin $D$ supplementation on outcome in the treatment of chronic hepatitis C. Gut59:A41. 